Article

\title{
Digestion Performance and Microbial Metabolic Mechanism in Thermophilic and Mesophilic Anaerobic Digesters Exposed to Elevated Loadings of Organic Fraction of Municipal Solid Waste
}

\author{
Yiming Gao ${ }^{1,2,3,4}$, Xiaoying Kong ${ }^{2,3,4, *}$, Tao Xing ${ }^{2,3,4}$, Yongming Sun ${ }^{2,3,4}$, Yi Zhang ${ }^{2,3,4,5}$, \\ Xingjian Luo ${ }^{2,3,4,5}$ and Yong Sun ${ }^{1, *}$ \\ 1 College of Engineering, Northeast Agricultural University, Harbin 150030, China; gaoym@ms.giec.ac.cn \\ 2 Guangzhou Institute of Energy Conversion, Chinese Academy of Sciences, Guangzhou 510640, China; \\ xingtao@ms.giec.ac.cn (T.X.); sunym@ms.giec.ac.cn (Y.S.); zhangyi@ms.giec.ac.cn (Y.Z.); \\ luoxj@ms.giec.ac.cn (X.L.) \\ 3 CAS Key Laboratory of Renewable Energy, Guangzhou 510640, China \\ 4 Guangdong Provincial Key Laboratory of New and Renewable Energy Research and Development, \\ Guangzhou 510640, China \\ 5 University of Chinese Academy of Sciences, Beijing 100049, China \\ * Correspondence: kongxy@ms.giec.ac.cn (X.K.), sunyong740731@163.com (Y.S.); Tel.:+86-020-87057783 (X.K.); \\ Tel.:+86-0451-55191670 (Y.S.)
}

Received: 8 February 2018; Accepted: 20 March 2018; Published: 17 April 2018

\begin{abstract}
Mesophilic and thermophilic anaerobic digestion reactors (MR and TR) for the organic fraction of municipal solid waste (OFMSW) were tested to reveal the differential microbial responses to increasing organic loading rate (OLR). MR exhibited faster adaptation and better performance at an OLR range of 1.0-2.5 $\mathrm{g} \mathrm{VS} \cdot \mathrm{L}^{-1} \cdot \mathrm{d}^{-1}$, with average profiles of a biogas yield of $0.38 \mathrm{~L} / \mathrm{gVS}_{\text {added }}{ }^{*} \mathrm{~d}$ at $0.5 \mathrm{~g} / \mathrm{L}^{*} \mathrm{~d}$ OLR and $0.69 \mathrm{~L} / \mathrm{gVS}_{\text {added }}{ }^{*} \mathrm{~d}$ at $2.5 \mathrm{~g} / \mathrm{L}^{*} \mathrm{~d}$ OLR, whereas TR had a biogas yield of $0.07 \mathrm{~L} / \mathrm{gVS}_{\text {added }}{ }^{*} \mathrm{~d}$ at $0.5 \mathrm{~g} / \mathrm{L}^{*} \mathrm{~d}$ OLR and $0.44 \mathrm{~L} / \mathrm{gVS}_{\text {added }}{ }^{*} \mathrm{~d}$ at $2.5 \mathrm{~g} / \mathrm{L}^{*} \mathrm{~d}$ OLR. The pyrosequencing results of amplicons revealed the microbial mechanisms of OFMSW anaerobic digestion. Larger shifts in the bacteria composition were observed in the TR with OLR elevation. For methanogens in both reactors, Methanothrix dominated in the MR while Methanosarcina was favored in the TR. Moreover, analysis of the mode and efficiency of metabolism between the MR and TR demonstrated different performances with more efficiency related to the limiting hydrolytic acid step.
\end{abstract}

Keywords: anaerobic digestion; organic fraction of municipal solid waste; microbial mechanisms; metabolism analysis

\section{Introduction}

The treatment and disposal of the organic fraction of municipal solid waste (OFMSW) represent major challenges worldwide owing to growing production levels [1]. Anaerobic digestion (AD) is an efficient and eco-friendly treatment to transform OFMSW into energy.

Mesophilic (30-40 ${ }^{\circ} \mathrm{C}$ ) and thermophilic $\left(50-60^{\circ} \mathrm{C}\right)$ AD systems are the most commonly used AD processes [2,3]. Several methods for increasing biogas production have been proposed, including raw material pretreatment and optimizing the fermenting digester [4,5]. According to the Arrhenius equation, chemical reaction rates could be doubled with a $10{ }^{\circ} \mathrm{C}$ temperature increase. Therefore, thermophilic AD is a possible strategy to improve the process efficiency owing to a higher reaction rates. Thermophilic AD shows several advantages such as higher loading rates of organic feedstock and a smaller pathogen degree [6]. Nevertheless, mesophilic AD would have a lower volatile fatty 
acid (VFA) concentration (especially propionate) and could usually support a higher organic loading rate (OLR) [7,8]. In general, OFMSW has a mutable complicated composition in the form of proteins, lipids, carbohydrates, and cellulose [9]. However, it is more uncertain whether the AD of OFMSW would lead to failure or low biogas production.

$\mathrm{AD}$ includes four major steps of microbial processes-hydrolysis, fermentation, acetogenesis, and methanogenesis-which are completed collectively by syntrophic interactions of different microorganisms [10]. Malfunctioning of the microbial population or activity at any one step can affect the overall microbial community, resulting in AD inefficiency or failure [11]. One common speculation for the lower efficiency of thermophilic AD at a high OLR is that higher VFA accumulation results in an imbalance between acidogenesis and methanogenesis in the microbial community [12].

To better understand the microbiome in AD reactors, molecular methods have been applied to replace traditional culture-dependent techniques [13]. With the development of next-generation sequencing technologies such as 454 pyrosequencing, a much larger amount of data can now be analyzed in a shorter period and has been successfully applied for examining the microbial community in different conditions [14], including investigations of the microbial diversity in AD [15]. Indeed, there is a great difference in the microbial community between mesophilic and thermophilic AD. For example, Guo reported that the methanogens Methanosaeta dominated the archaeal community in a mesophilic reactor (MR), while Methanothermobacter and Methanoculleus were favored in a thermophilic reactor (TR) [16]. Although various sequencing data have been obtained, information on the microbial community in AD is still very limited.

The aim of the study was to compare the dynamics and structure of the microbial communities using high-throughput sequencing, to compare metabolism between two lab-scale temperature-state ADs (MR and TR) that were operated at a gradually increasing OLR, and to determine their respective performances. Due to the inoculum, thermophilic AD took a longer time to adapt.

\section{Results and Discussion}

\subsection{Performance of the Reactors}

Initially, the OLR of the MR was gradually elevated with a gradient of $0.5 \mathrm{gVS} \cdot \mathrm{L}^{-1} \cdot \mathrm{d}^{-1}$ from an initial level of $0.5 \mathrm{gVS} \cdot \mathrm{L}^{-1} \cdot \mathrm{d}^{-1}$ over 7 days. The TR was acclimated with low concentrations of OFMSW for 43 days at an OLR of $0.5 \mathrm{gVS} \cdot \mathrm{L}^{-1} \cdot \mathrm{d}^{-1}$. Subsequently, the OLR of the MR was increased with a gradient of $0.5 \mathrm{gVS} \cdot \mathrm{L}^{-1} \cdot \mathrm{d}^{-1}$ every week over the next two weeks, and was increased by $0.5 \mathrm{gVS} \cdot \mathrm{L}^{-1} \cdot \mathrm{d}^{-1}$ every 25 days from Day 57 to Day 106.

Profiles of the biogas yield (SBY) of the added OLR, methane production and concentration, intermediate alkalinity to partial alkalinity ratio (IA:PA), and $\mathrm{pH}$ of the two reactors are shown in Figure 1. The two reactors showed different performances at the low OLR concentration, and the MR exhibited a much better ability for biogas and methane production, implying that a normal atmospheric temperature seed biomass allows for stronger adaptability of mesophilic AD. In the MR, the SBY increased in the first 7 days, peaking at $0.54 \mathrm{~L} / \mathrm{gVS}_{\text {added }}{ }^{*} \mathrm{~d}$, decreased over the next 25 days, and then showed an upward trend in the latter three stages. The SBY of the MR was $0.55 \mathrm{~L} / \mathrm{gVS}_{\text {added }}{ }^{*} \mathrm{~d}$ at $2 \mathrm{~g} / \mathrm{L}^{*} \mathrm{~d}$ OLR and was $0.69 \mathrm{~L} / \mathrm{gVS}_{\text {added }}{ }^{*} \mathrm{~d}$ at $2.5 \mathrm{~g} / \mathrm{L}^{*} \mathrm{~d}$ OLR. In the TR, the SBY remained steady in the first 43 days, increased to $0.26 \mathrm{~L} / \mathrm{gVS}_{\text {added }}{ }^{*} \mathrm{~d}$ over the next week, and then showed an initial decrease, followed by an upward trend in the last 50 days. The SBY of the TR was $0.16 \mathrm{~L} / \mathrm{gVS}_{\text {added }}{ }^{*} \mathrm{~d}$ at $2 \mathrm{~g} / \mathrm{L}^{*} \mathrm{~d}$ OLR and was $0.44 \mathrm{~L} / \mathrm{gVS}_{\text {added }}{ }^{*} \mathrm{~d}$ at $2.5 \mathrm{~g} / \mathrm{L}^{*} \mathrm{~d}$ OLR. Thus, in this experiment, the MR showed greater biogas production, and had stronger adaptability and gas production efficiency than the TR for each OLR tested.

The $\mathrm{pH}$ of the two digesters ranged from 7.0 to 7.5 and remained in a stable state, as the suggested condition of anaerobic fermentation [17]. The IA:PA of alkalinity remained below 1 essentially the whole time for both reactors, implying the stability of the reactors [18]. However, at Day 35 of the TR, the IA:PA value was 1.16, suggesting that the microbial community showed preliminary adaptation to 
the production of organic acids. There was no accumulation of VFAs, as no VFAs could be detected. In addition, the $\mathrm{NH}_{3}-\mathrm{N}$ concentration in both reactors was below $500 \mathrm{mg} / \mathrm{L}$ from start to finish, indicating that the effect of ammonia on the methane yield was negligible in both reactors $[19,20]$. Therefore, there were minimal inhibition effects in both reactors throughout the operation.
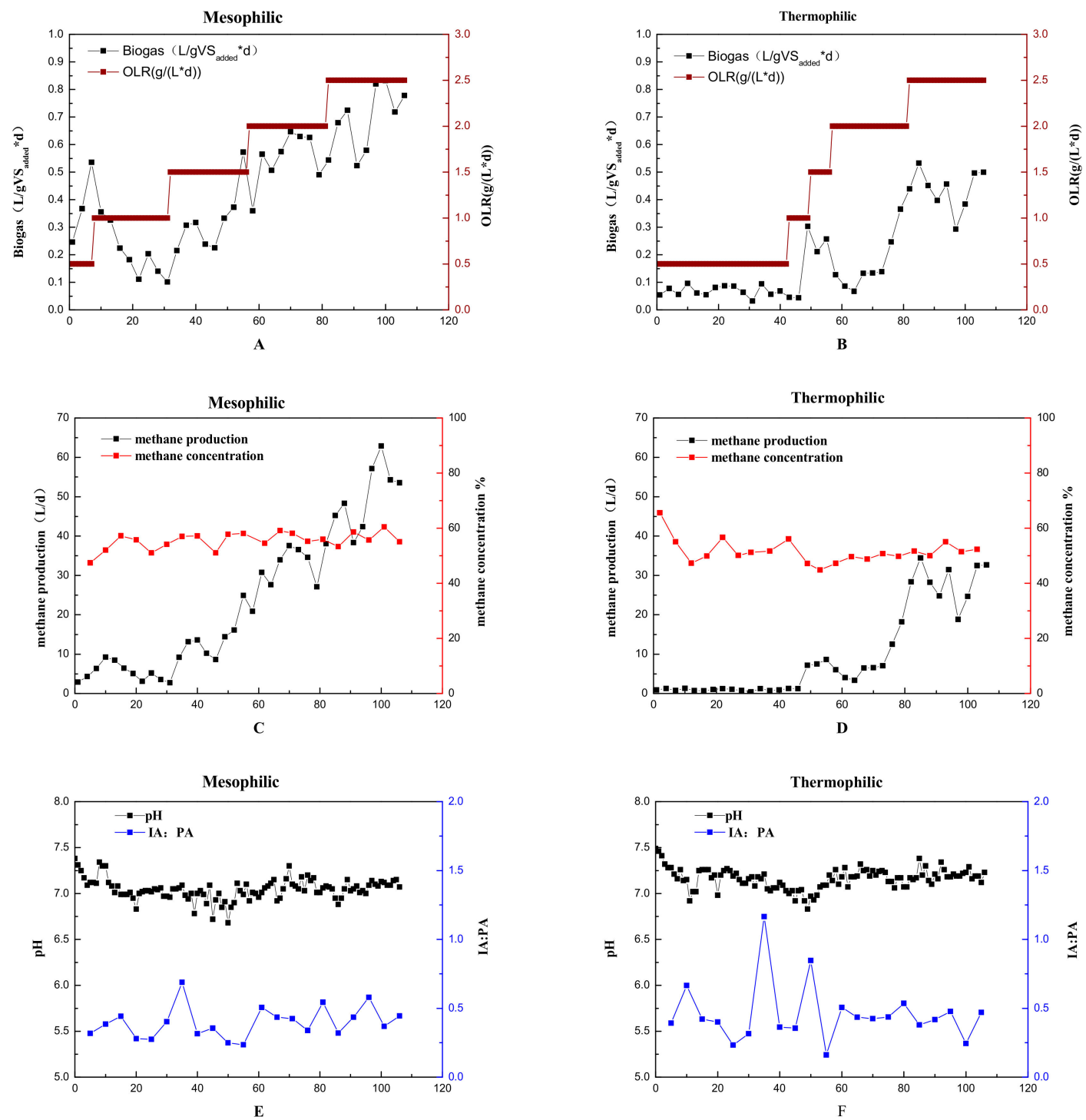

Figure 1. Evolution of biogas/methane yield (A,B), methane production and percentage $(\mathbf{C}, \mathbf{D}), \mathrm{pH}$, and intermediate alkalinity to partial alkalinity (IA:PA) ratio (E,F) in both reactors.

\subsection{Bacterial Communities Revealed by Pyrosequencing}

Comparison of the sequencing data with the database and taxonomic analysis at the species level were carried out using a high-throughput pyrosequencing technique to investigate the microbial community structures and dynamics. The samples were collected at Days 0 (inoculum), 42, 81, and 106 from the MR and TR. Table 1 shows the sequence number (Seq num) and the alpha diversity estimators of three indices (Shannon, ACE, Chao1) for each sample. The Shannon index reflects the community diversity, and the ACE and Chao 1 indices are used to estimate the total number of species. The higher Shannon, ACE, and Chao 1 index values of the MR mutually implied the higher diversity of the bacterial community in this reactor. Nevertheless, Sample T42 had higher values of the diversity estimators than the inoculum, implying adaptation and an intense change of the bacterial community 
in the TR. For the TR, the values of the diversity estimators increased throughout most of the operation, and a subsequent decline in diversity indicated that the dominant bacterial community had a greater advantage in the end (Table 2). For the archaeal community, the diversity showed a different trend between the MR and TR, in which the diversity of the archaeal community increased from Day 0 to Day 106, indicating that more archaea were involved in the process of methane production than in the inoculum. The TR showed the highest diversity of the archaeal community at Day 42 , and then decreased in the latter days. At Day 106, the TR had the lowest diversity of the archaeal community, implying that fewer archaea were involved in the process of methane production than in the MR. Overall, the MR and TR showed decreasing trends in the diversity of the bacterial community during the running time; the diversity of the archaeal community increased in the MR and decreased in the TR. The diversity of the MR was greater than that of the TR for both bacteria and archaea.

Table 1. Diversity indices of bacterial $16 \mathrm{~S}$ rRNA gene libraries obtained from pyrosequencing. All values were calculated at the 0.03 distance limit.

\begin{tabular}{ccccc}
\hline Sample ID & Seq num & Shannon & ACE & Chao1 \\
\hline Inoculum & 36,968 & 4.83 & 2085.72 & 2003.94 \\
M42 & 50,721 & 4.35 & 1993.82 & 1993.82 \\
M81 & 34,881 & 3.94 & 1482.31 & 1196.27 \\
M106 & 43,495 & 3.87 & 1333.54 & 1290.58 \\
T42 & 48,268 & 4.84 & 2107.76 & 2010.29 \\
T81 & 24,640 & 3.53 & 819.58 & 740.92 \\
T106 & 39,521 & 3.28 & 812.26 & 754.70 \\
\hline
\end{tabular}

Table 2. Diversity indices of archaeal $16 \mathrm{~S}$ rRNA gene libraries obtained from pyrosequencing. All values were calculated at the 0.03 distance limit.

\begin{tabular}{ccccc}
\hline Sample ID & Seq num & Shannon & ACE & Chao1 \\
\hline Inoculum & 37,349 & 1.81 & 400.96 & 358.27 \\
M42 & 35,726 & 1.91 & 479.86 & 395.59 \\
M81 & 38,486 & 2.14 & 597.13 & 458.31 \\
M106 & 38,703 & 2.33 & 622.17 & 497.01 \\
T42 & 38,494 & 2.64 & 608.64 & 552.93 \\
T81 & 38,095 & 2.12 & 476.57 & 330.21 \\
T106 & 39,425 & 1.13 & 175.41 & 158 \\
\hline
\end{tabular}

The phylum-level distribution of sequences is shown in Figure 2. For the bacteria, seven phyla existed in both digests with a relative abundance higher than $1 \%$. Chloroflexi was the major phylum at the early stage for both digests. Bacteroidetes was the dominant phylum in the MR while Thermotogae was dominant in the TR for almost the entire process. Firmicutes appeared in both reactors throughout the whole period and its relative abundance was much higher in the TR than in the MR. Synergistetes and Proteobacteria existed throughout the operation period, indicating that these phyla might play important roles in both reactors even though their proportions were relatively low.

Moreover, the phyla distributions in the two digesters showed different patterns of change during the operation time. In the MR, the relative abundance of Chloroflexi decreased gradually after an initial increase. The proportion of the phylum Bacteroidetes increased obviously to $49.49 \%$ while those of Synergistete and Proteobacteria decreased to $7.11 \%$ and $2.47 \%$, respectively. Firmicutes remained steady from Day 0 to Day 106. Cloacimonetes appeared at every stage in the MR, but only appeared initially in the TR. In the TR, the proportions of both Chloroflexi and Bacteroidetes showed a distinct downward trend and reached a very low level (0.25\% and 3.41\%, respectively) at Day 106 . Firmicutes increased significantly and was the most abundant phylum (42.36\%) at Day 106. Figure 2 shows that Thermotogae remained stable at the first and last stages (from Day 0 to Day 42 and from Day 81 to Day 106) but increased by up to $32.43 \%$ from Day 42 to 81 , whereas the abundance of Proteobacteria declined 
slightly. After 106 days of operation, the two ADs showed a big difference in bacterial communities with Bacteroidetes dominant in the MR while Thermotogae and Firmicutes were dominant in the TR. Analysis of sequencing data provides a better approach to explaining the bacterial communities at the subdivision level. Hence, the relative abundance at the genus level was computed in every sample. In total, 39 genera were detected with a proportion higher than $0.1 \%$ in at least one sample screened as the abundant genera. The distributions at the genus level of each sample are shown in Figure 3.

\section{Distribution Barplot}

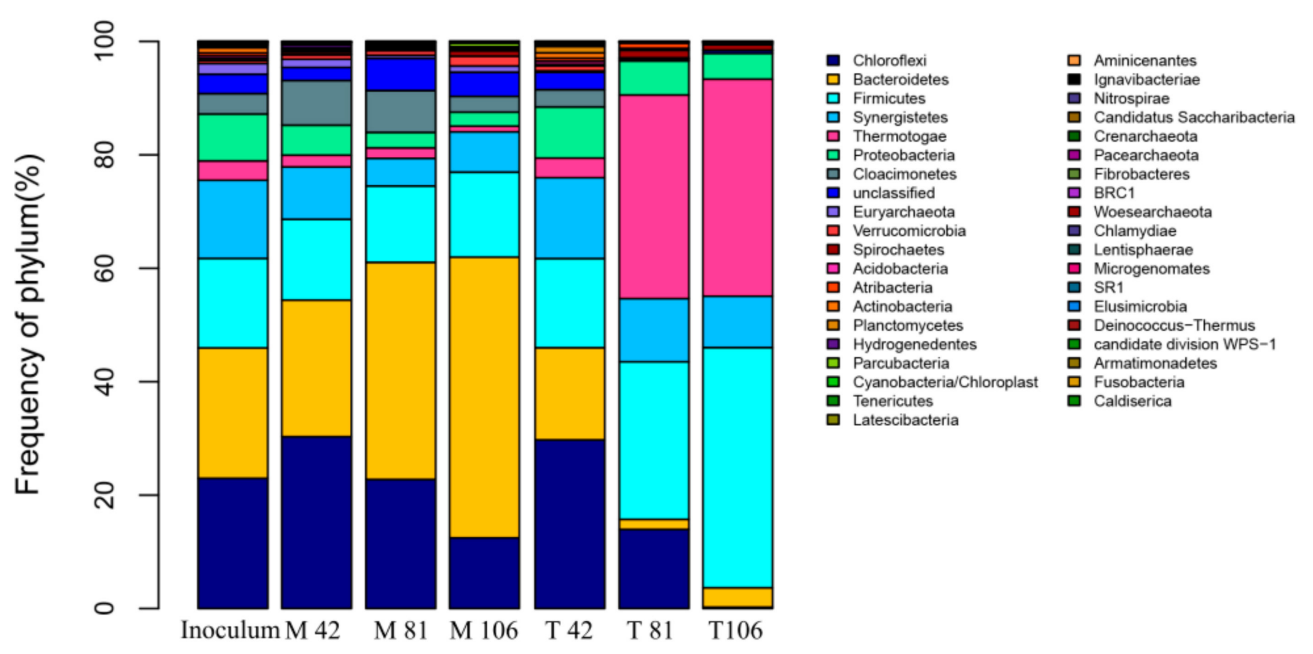

Figure 2. Taxonomic compositions of bacterial communities at the phylum level in each sample retrieved from pyrosequencing. The number in the sample names represents the day when sampling occurred. T: thermophilic reactor; M: mesophilic reactor.

As mentioned above, Chloroflexi was present in large proportions and then decreased in both reactors. The distributions also showed a downward trend in this phylum at the genus level. The major genus classified to the phylum Chloroflexi was Levilinea, which represented the greatest proportion in the inoculum as well as in samples M42, M81, T42, and then decreased dramatically from $19.27 \%$ to $8.87 \%$ in the MR and from $18.15 \%$ to 0 in the TR during operation. Levilinea can convert several carbohydrates to acetate and hydrogen under conditions of a high sodium concentration [21]. The genera Longilinea and Ornatilinea also decreased in both reactors, which might indicate their potential ability for organic matter degradation under hydrolysis acidification conditions [22].

For the MR, the genera in the dominant phylum Bacteroidetes showed obvious changes over the operation time. Lutaonella decreased initially and then increased significantly to $19.59 \%$ in M106, as this genus can use many organic acids and amino acids [23]. Mariniphaga and Sunxiuqinia showed an obvious decline in abundance. The former takes advantage of lipids and the latter ferments sugars with many kinds of acids as major fermentation products [24,25].

In the TR, the major genus assigned to the dominant phylum Thermotogae was Fervidobacterium, reaching very high levels of $35.63 \%$ at Day 81 and $38.07 \%$ at Day 106, which suggested its activities in acetate oxidation [26]. The relative abundance of Clostridium_III classified to the phylum Firmicutes also increased dramatically to $22.89 \%$ at Day 106 ; Clostridium_III converts complex macromolecules into alcohols, hydrogen, carbon dioxide, and volatile fatty acids [27]. 


\begin{tabular}{|c|c|c|c|c|c|c|c|c|}
\hline$\%$, Relative Abur & & Inoculum & M42 & M81 & M106 & T42 & $\mathrm{T} 81$ & T106 \\
\hline Acidobacteria & Gp18 & 0.42 & 0 & 0 & 0 & 0.49 & 0 & 0 \\
\hline & Gp6 & 0 & 0 & 0 & 0 & 0 & 0.29 & 0 \\
\hline Atribacteria & Atribacteria_genera_incertae_sedis & 0.52 & 0.39 & 0 & 0 & 0.54 & 0.93 & 0.22 \\
\hline & & 0 & 0 & 0 & 0 & 0 & 0 & 0 \\
\hline Bacteroidetes & Bacteroides & 0 & 0 & 2.51 & 4.53 & 0 & 0 & 0 \\
\hline & Lutaonella & 11.68 & 2. 47 & 10.41 & 19. 59 & 7. 98 & 0 & 0 \\
\hline & Macellibacteroides & 0 & 0 & 0.27 & 0.45 & 0 & 0 & 0 \\
\hline & Mangrovibacterium & 0 & 0.44 & 0.23 & 0 & 0.52 & 0 & 0 \\
\hline & Mariniphaga & 3.46 & 7. 14 & 5.92 & 1.75 & 2. 29 & 0 & 0 \\
\hline & Meniscus & 1.26 & 2. 36 & 2.97 & 1.3 & 0.76 & 0 & 0 \\
\hline & Paludibacter & 0 & 0 & 0.67 & 0.97 & 0 & 0 & 0 \\
\hline & Petrimonas & 0 & 0 & 0 & 0 & 0 & 0.22 & 2.88 \\
\hline & Prevotella & 0 & 0 & 0 & 0.66 & 0 & 0 & 0 \\
\hline & Proteiniphilum & 0.95 & 0 & 0 & 0 & 0 & 0 & 0 \\
\hline & Sunxiuqinia & 0.7 & 7. 38 & 5.18 & 3.6 & 0.78 & 0 & 0 \\
\hline & Tangfeifania & 0 & 0 & 0.4 & 0 & 0 & 0 & 0 \\
\hline Chloroflexi & Bellilinea & 0.53 & 0.84 & 0.46 & 0 & 0.63 & 0.37 & 0 \\
\hline & Leptolinea & 0.48 & 0 & 0 & 0 & 0 & 0 & 0 \\
\hline & Levilinea & 13. 15 & 19.27 & 16.46 & 8.87 & 18.15 & 6. 69 & 0 \\
\hline & Longilinea & 2.36 & 4.29 & 1.46 & 0.86 & 3. 37 & 0.83 & 0.14 \\
\hline & Ornatilinea & 2.51 & 3.09 & 3.24 & 1.37 & 4. 37 & 5.93 & 0 \\
\hline & Pelolinea & 0.69 & 0 & 0 & 0 & 0.45 & 0 & 0 \\
\hline Cloacimonetes & Candidatus_Cloacamonas & 3. 61 & 7.87 & 7. 39 & 2. 78 & 3.05 & 0 & 0 \\
\hline Euryarchaeota & Methanothrix & 1.83 & 1.36 & 0.51 & 0.99 & 0 & 0 & 0 \\
\hline Firmicutes & Acetanaerobacterium & 0 & 0.4 & 0 & 0 & 0 & 0 & 0 \\
\hline & Anaeroarcus & 0 & 0 & 0.27 & 0 & 0 & 0 & 0 \\
\hline & Anaerovorax & 0.74 & 0.54 & 0.29 & 0.6 & 0.44 & 0 & 0 \\
\hline & Caloramator & 0 & 0 & 0 & 0 & 0 & 0.17 & 0 \\
\hline & Catabacter & 0.41 & 0 & 0 & 0 & 0 & 0 & 0 \\
\hline & Cellulosibacter & 0 & 0 & 0 & 0 & 0 & 0.2 & 0.3 \\
\hline & Christensenella & 0.44 & 0 & 0 & 0 & 0.53 & 0 & 0.15 \\
\hline & Clostridium_sensu_stricto & 0 & 0 & 0 & 0 & 0 & 0.28 & 0.18 \\
\hline & Clostridium_III & 0 & 0 & 0 & 0.44 & 0 & 12.46 & 22.89 \\
\hline & Clostridium IV & 0 & 0 & 0.4 & 1.2 & 0 & 0.62 & 0.44 \\
\hline & Clostridium_XIVa & 0 & 0.54 & 0.4 & 0.66 & 0 & 1.15 & 4. 57 \\
\hline & Coprothermobacter & 0 & 0 & 0 & 0 & 0 & 0 & 0.16 \\
\hline & Defluviitalea & 0 & 0 & 0 & 0 & 0 & 2.81 & 2.82 \\
\hline & Ercella & 0 & 0.44 & 0.38 & 0 & 0 & 0 & 0 \\
\hline & Garciella & 0 & 0 & 0 & 0 & 0 & 0 & 0.21 \\
\hline & Gracilibacter & 0 & 0 & 0 & 0 & 0 & 0.24 & 0.25 \\
\hline & Hydrogenispora & 0 & 0 & 0 & 0 & 0 & 0.71 & 1. 54 \\
\hline & Intestinimonas & 0 & 0 & 0 & 0 & 0 & 0 & 0.3 \\
\hline & Lactobacillus & 0 & 0.4 & 0 & 0 & 0 & 0.48 & 0 \\
\hline & Lutispora & 0 & 0 & 0 & 0 & 0 & 0.23 & 0.18 \\
\hline & Pelotomaculum & 0 & 0 & 0 & 0 & 0 & 0.46 & 0 \\
\hline & Phascolarctobacterium & 0 & 0.73 & 0.52 & 0.69 & 0 & 0 & 0 \\
\hline & Proteiniborus & 0 & 0 & 0 & 0 & 1.05 & 0 & 0 \\
\hline & Pseudobacteroides & 0 & 0 & 0 & 0 & 0 & 0 & 0.25 \\
\hline & Romboutsia & 0.43 & 0 & 0 & 0 & 0.68 & 0 & 0 \\
\hline & Ruminococcus & 0 & 0.66 & 0 & 0 & 0 & 0 & 0.32 \\
\hline & Saccharofermentans & 2.89 & 1.26 & 1.26 & 1.15 & 1.83 & 0 & 0 \\
\hline & Syntrophomonas & 0.47 & 0.67 & 0.44 & 0.52 & 0 & 3.32 & 1. 77 \\
\hline & Tepidanaerobacter & 0 & 0 & 0 & 0 & 0 & 0 & 0.17 \\
\hline & Tepidimicrobium & 0 & 0 & 0 & 0 & 0 & 0 & 0.13 \\
\hline & Thermoflavimicrobium & 0 & 0 & 3. 16 & 3. 34 & 0 & 0 & 0 \\
\hline & Thermoflavimicrobium & 0 & 0.36 & 0 & 0 & 0 & 0 & 0 \\
\hline & Thermosyntropha & 0 & 0 & 0 & 0 & 0 & 0.45 & 0 \\
\hline & Turicibacter & 0 & 0 & 0 & 0.54 & 0 & 0 & 0 \\
\hline Hydrogenedentes & Candidatus_Hydrogenedens & 0 & 0.56 & 0 & 0 & 0 & 0 & 0 \\
\hline Parcubacteria & Parcubacteria_genera_incertae_sedis & 0 & 0 & 0 & 0.65 & 0 & 0 & 0 \\
\hline Planctomycetes & Thermogutta & 0 & 0 & 0 & 0 & 0.92 & 0 & 0 \\
\hline Proteobacteria & Citrobacter & 0 & 0 & 0 & 0 & 0 & 0 & 0.14 \\
\hline & Desulfatibacillum & 1.08 & 0 & 0 & 0 & 1.28 & 2.64 & 0.22 \\
\hline & Smithella & 2.08 & 2.52 & 1.12 & 1.22 & 2. 32 & 0 & 0 \\
\hline & Syntrophobacter & 0 & 0 & 0.26 & 0 & 0 & 0 & 0 \\
\hline & Syntrophorhabdus & 2. 06 & 0.73 & 0 & 0 & 1.87 & 0 & 0 \\
\hline & Syntrophus & 0.86 & 0 & 0 & 0 & 0.54 & 0 & 0 \\
\hline & Tepidiphilus & 0 & 0 & 0 & 0 & 0 & 2. 89 & 3. 71 \\
\hline Spirochaetes & Sphaerochaeta & 0 & 0 & 0 & 0.43 & 0 & 0 & 0 \\
\hline & Treponema & 0 & 0 & 0 & 0.53 & 0 & 1.34 & 1.02 \\
\hline Synergistetes & Aminivibrio & 3.93 & 1.72 & 1.69 & 3. 12 & 3. 91 & 0 & 0 \\
\hline & Aminomonas & 0 & 0 & 0 & 0 & 0 & 1.57 & 0.19 \\
\hline & Anaerobaculum & 0 & 0 & 0 & 0 & 0 & 7. 08 & 7. 99 \\
\hline & Cloacibacillus & 4.45 & 5.91 & 2.83 & 3.59 & 6.27 & 0.16 & 0 \\
\hline & Thermovirga & 4. 79 & 1.31 & 0 & 0 & 3. 75 & 1.67 & 0.44 \\
\hline Thermotogae & Defluviitoga & 2. 69 & 1.26 & 0 & 0 & 2.58 & 0 & 0.19 \\
\hline & Fervidobacterium & 0 & 0 & 0 & 0 & 0 & 35.63 & 38.07 \\
\hline & Mesotoga & 0.71 & 0.81 & 1.71 & 0.95 & 0.88 & 0.26 & 0 \\
\hline Verrucomicrobia & Subdivision3 genera incertae sedis & 0 & 0 & 0.36 & 0.97 & 0.52 & 0 & 0 \\
\hline
\end{tabular}

Figure 3. Taxonomic compositions of bacterial communities at the genus level for the sequences retrieved from each sample. Grey, inoculum; red, mesophilic reactor (MR); purple, thermophilic reactor (TR) (higher relative abundances are shown in deeper colors). 


\subsection{Dynamics of Methanogen Communities}

The archaeal community dynamics were also revealed by high-throughput pyrosequencing targeting $16 \mathrm{~S}$ rRNA gene segments. The patterns of relative abundance at the genus level of archaea are shown in Figure 4. Overall, methanogens had lower diversity than the bacterial community partly because of the intrinsically low phylogenetic diversity of methanogens.

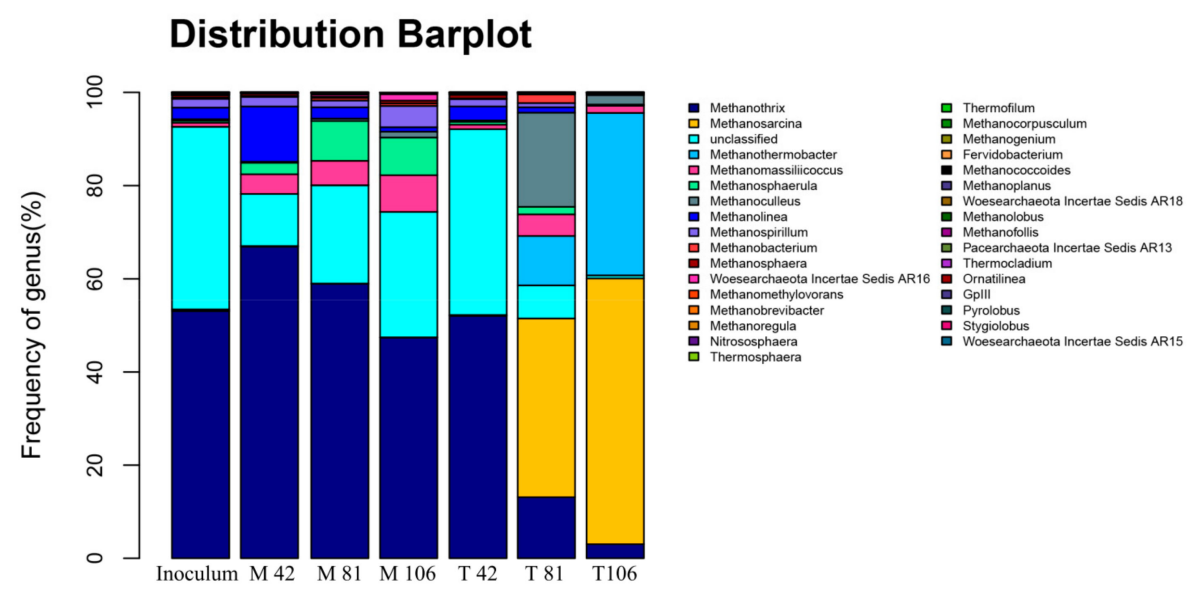

Figure 4. Taxonomic compositions of methanogens at the genus level in each sample retrieved from pyrosequencing. The sample names are the same as those described in Figure 2.

Methanothrix was the most abundant methanogen in the MR throughout the operation and at Day 42 of the TR, and is considered to be the main methanogen involved in anaerobic fermentation [28]. Moreover, Methanothrix accounted for the majority of the sequence reads in the MR, while Methanosarcina was most abundant for the TR at Day 81 and Day 106 at the genus level, which is commonly observed in thermophilic digesters. Methanothermobacter ranked second in relative abundance in the TR at Days 81 and 106, which also implied a relation to hydrogenotrophic methanogens. In general, hydrogenotrophic methanogen species are more commonly detected in thermophilic digesters [28].

The genus Methanothrix was dominant in the MR throughout the running time with a relative abundance of $66.89 \%$ at Day $42,58.94 \%$ at Day 81 , and $47.39 \%$ at Day 106, representing an acetoclastic microorganism [29]. Comparatively, Methanothrix was only the most abundant genus (52.05\%) in the TR at Day 42, and then Methanosarcina became the most abundant of the TR methanogens at 38.37\% by Day 81 and at $57.07 \%$ by Day 106; Methanosarcina can produce methane by using $\mathrm{H}_{2} / \mathrm{CO}_{2}$, acetate, and methanol [30]. Methanothermobacter also played an important role in the TR, accounting for $10.62 \%$ at Day 81 and $34.86 \%$ at Day 106, indicating important effects of hydrogenotrophic methanogens [30]. Remarkably, Methanoculleus had a relative abundance of $20.20 \%$ with an ability for hydrogenotrophic activity [31]. In consideration of the rapid change in the OLR from Day 42 to Day 81, the microbial community might also go through a dramatic change in the TR. Overall, acetoclastic methanogens were dominant in the MR, while hydrogenotrophic methanogens were dominant in the TR, implying hydrogenotrophic and acetoclastic metabolism processes as the main pathways to methane production in the TR and MR, respectively.

\subsection{Linkage between Metabolism and Reactor Performances}

To further understand the impact of OLR and temperature on microbial communities, analysis of metabolic pathways was conducted. Based on the results of the two-level classification of the PICRUSt function, the differences of sample or intergroup abundance were compared, and the function of the significant differences between the samples or the abundance of the group was evaluated. Bacteria metabolism was compared between samples M106 and T106 to reveal the effect of the operation 
condition in both reactors. For bacteria, all of the metabolic functions are shown in Figure 5. Compared with that of the TR, the metabolism of the MR showed more active trends in amino acid metabolism, lipid metabolism, metabolism of cofactors and vitamins, carbohydrate metabolism, and energy metabolism, which contributed to the acid production step in anaerobic fermentation. Due to the complex substrate of the OFMSW and no accumulation of VFAs, the rate-limiting step was considered to be hydrolytic acid production. Amino acid metabolism, lipid metabolism, and carbohydrate metabolism refer to the degradation of amino acids, lipids, and carbohydrates, respectively. To a certain extent, the problem of a slow acid production rate has been solved because of the improvement of these metabolic pathways in the MR. By contrast, in the TR, cell motility, translation, and membrane transport were more active than in the MR, showing greater potential to adapt to environmental changes.
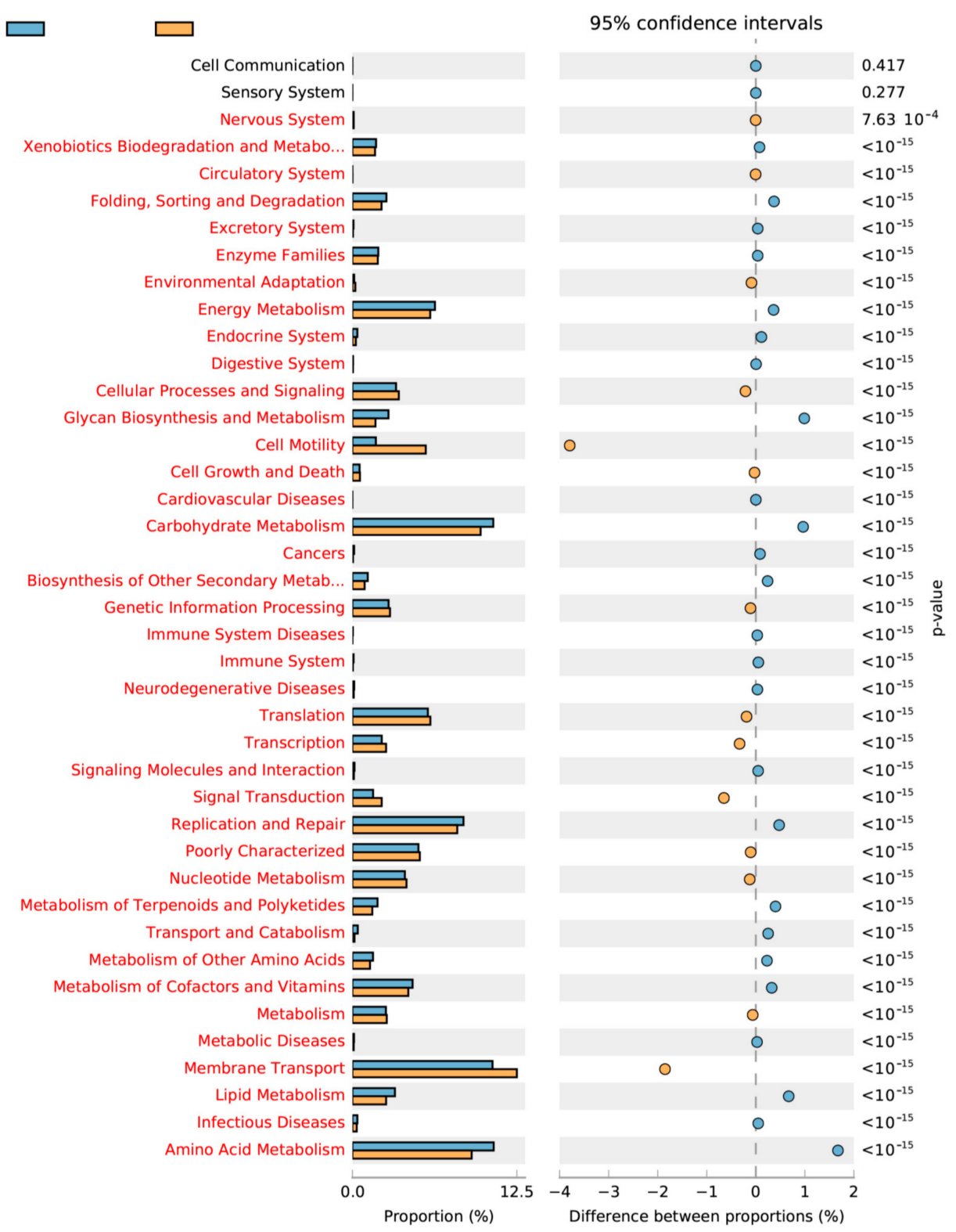

Figure 5. Different proportions of bacteria metabolic function at $95 \%$ confidence intervals between the MR and TR at Day 106.

For archaea, energy metabolism is considered as the primary methane production process in anaerobic fermentation [32]. The sequence patterns for metabolism are shown in Figure 6, demonstrating a proportion in the TR of $11.12 \%$, which is much greater than the $8.39 \%$ in the MR. Thus, 
the TR might have more potential for methane production in the presence of a more acidic substrate in AD. Meanwhile, amino acid metabolism and lipid metabolism in the MR were more active than in the TR, which might be the main cause of the difference in AD performance.

\begin{tabular}{|c|c|c|c|c|c|c|c|}
\hline$\square$ & \multicolumn{5}{|c|}{$95 \%$ confidence intervals } & \multirow{2}{*}{\multicolumn{2}{|c|}{1.000}} \\
\hline Immune System | & \multicolumn{5}{|c|}{0} & & \\
\hline Sensory System | & \multicolumn{5}{|c|}{0} & \multicolumn{2}{|l|}{1.000} \\
\hline Cardiovascular Diseases | & \multicolumn{5}{|c|}{0} & 1.000 & \\
\hline Cell Communication | & \multicolumn{5}{|c|}{0} & 1.000 & \\
\hline Signal Transduction 日 & \multicolumn{5}{|c|}{0} & 0.401 & \\
\hline Cell Growth and Death & \multicolumn{5}{|c|}{0} & 0.167 & \\
\hline Endocrine System | & \multicolumn{5}{|c|}{ b } & $<10^{-15}$ & \\
\hline Genetic Information Processing בح & \multicolumn{5}{|c|}{1} & $<10^{-15}$ & \\
\hline Folding, Sorting and Degradation & \multicolumn{5}{|c|}{0} & $<10^{-15}$ & \\
\hline Excretory System & \multicolumn{5}{|c|}{ Q } & $<10^{-15}$ & \\
\hline Enzyme Families $⿴$ & \multicolumn{5}{|c|}{0} & $<10^{-15}$ & \\
\hline Environmental Adaptation | & \multicolumn{5}{|c|}{ ○ } & $<10^{-15}$ & \\
\hline Energy Metabolism & \multicolumn{5}{|c|}{1} & $<10^{-15}$ & \\
\hline Xenobiotics Biodegradation and Metabo... & \multicolumn{5}{|c|}{ o } & $<10^{-15}$ & \\
\hline Digestive System b & \multicolumn{5}{|c|}{0} & $<10^{-15}$ & \\
\hline Circulatory System | & \multicolumn{5}{|c|}{0} & $<10^{-15}$ & \\
\hline Glycan Biosynthesis and Metabolism 日 & \multicolumn{5}{|c|}{10} & $<10^{-15}$ & \\
\hline Cell Motility $\overline{\text { 日 }}$ & \multicolumn{5}{|c|}{0} & $<10^{-15}$ & \\
\hline Carbohydrate Metabolism & \multicolumn{5}{|c|}{1} & $<10^{-15}$ & \\
\hline Cancers | & \multicolumn{5}{|c|}{0} & $<10^{-15}$ & ע \\
\hline Biosynthesis of Other Secondary Metab... 日 & & & 0 & & & $<10^{-15}$ & $\frac{\sqrt{0}}{2}$ \\
\hline Cellular Processes and Signaling & & 0 & 1 & & & $<10^{-15}$ & $\dot{a}$ \\
\hline Immune System Diseases | & & & 0 & & & $<10^{-15}$ & \\
\hline Transport and Catabolism & & & 0 & & & $<10^{-15}$ & \\
\hline Infectious Diseases B & & & d & & & $<10^{-15}$ & \\
\hline Translation & & & 1 & & 0 & $<10^{-15}$ & \\
\hline Transcription & & & 0 & & & $<10^{-15}$ & \\
\hline Signaling Molecules and Interaction | & & & 0 & & & $<10^{-15}$ & \\
\hline Replication and Repair & & & I & 0 & & $<10^{-15}$ & \\
\hline Poorly Characterized & 0 & & 1 & & & $<10^{-15}$ & \\
\hline Nucleotide Metabolism & & & 1 & 0 & & $<10^{-15}$ & \\
\hline Neurodegenerative Diseases & & & 0 & & & $<10^{-15}$ & \\
\hline Nervous System | & & & 0 & & & $<10^{-15}$ & \\
\hline Metabolism of Terpenoids and Polyketides $\square$ & & & 1 & 0 & & $<10^{-15}$ & \\
\hline Metabolism of Other Amino Acids 日 & & & 0 & & & $<10^{-15}$ & \\
\hline Metabolism of Cofactors and Vitamins & & & 10 & & & $<10^{-15}$ & \\
\hline Metabolism ק & & 0 & 1 & & & $<10^{-15}$ & \\
\hline Metabolic Diseases | & & & 0 & & & $<10^{-15}$ & \\
\hline Membrane Transport & c & & 1 & & & $<10^{-15}$ & \\
\hline Lipid Metabolism $\square$ & & & । & 0 & & $<10^{-15}$ & \\
\hline Amino Acid Metabolism & & & I & & 0 & $<10^{-15}$ & \\
\hline$\frac{1}{12.0}$ & -2 & $\frac{1}{-1}$ & $\frac{1}{0}$ & $\frac{1}{1}$ & $\frac{1}{2}$ & 3 & \\
\hline Proportion (\%) & Differen & e betw & een $\mathrm{p}$ & oropor & tions (\%) & & \\
\hline
\end{tabular}

Figure 6. Different proportions of archaeal metabolic function at $95 \%$ confidence intervals between the MR and TR at Day 106.

\section{Materials and Methods}

\subsection{Anaerobic Digesters}

Two identical $60 \mathrm{~L}$ cylindrical anaerobic reactors with $50 \mathrm{~L}$ working volume and a heating apparatus were used to maintain internal temperatures at $55 \pm 1{ }^{\circ} \mathrm{C}$ and $35 \pm 1{ }^{\circ} \mathrm{C}$ for the TR and $\mathrm{MR}$, respectively. The inoculum was taken from a normal atmospheric-temperature AD used for treating dairy farm wastewater (Kaiping, Guangzhou Province, China). Before feeding the reactors, the inoculum was filtered through a $1 \mathrm{~mm}$ sieve and starved for one week. The seed biomass was diluted with double-distilled water to $9.7 \pm 0.7 \mathrm{gVS} / \mathrm{L}$ in reactors. The MSW was periodically obtained from a waste yard (Shaoguan, Guangdong province, China). The inorganic portions of the MSW such 
as glass and plastics were removed manually. The selected MSW was subpackaged in several sealing bags and stored at $-18^{\circ} \mathrm{C}$ after being ground and homogenized. The basic characteristics of the MSW are shown in Table S1 of the Supplementary Materials. The hydraulic retention time was 20 days, and the reactors were fed once a day. A stirrer was set at a speed of $60 \mathrm{rpm}$ and ran constantly during the discharging and feeding time; at other time, it operated for 3 min every $15 \mathrm{~min}$. The biogas was measured using a wet gas meter (Haide, Dalian, China).

\subsection{Chemical Analysis}

The total and volatile solid contents were measured by standard analytical methods for the examination of water and wastewater [33]. The $\mathrm{C}, \mathrm{H}$, and $\mathrm{N}$ contents were measured using a Vario EL element analyzer (VarioEL cube, Elementar, Langenselbold, Germany). The concentrations of $\mathrm{NH}_{3}-\mathrm{N}$ and COD were analyzed using a commercially available kit (DR2800, Hach, Loveland, CO, USA). The $\mathrm{pH}$ was measured using a $\mathrm{pH}$ meter (pHS-3C, Rex, Shanghai, China). The contents of formate and VFAs - mainly acetate, propionate, and butyrate-were analyzed by high-performance liquid chromatography (e2695, Waters, Boston, MA, USA) using a refractive index detector and HPX-87 column. The mobile phase was $0.005 \mathrm{~N} \mathrm{H}_{2} \mathrm{SO}_{4}$ with a flow rate of $0.5 \mathrm{~mL} / \mathrm{min}$, and the temperature of the column was $50{ }^{\circ} \mathrm{C}$. Alkalinity was measured with $0.25 \mathrm{~N} \mathrm{H}_{2} \mathrm{SO}_{4}$ to points of $\mathrm{pH} 5.7$ and 4.3, to obtain data on IA, PA, and total alkalinity using a Titroline 5000 titrator (Julabo, Seelbach, Germany).

\subsection{DNA Extraction and Amplification}

DNA extraction was performed with an E.Z.N.A ${ }^{\mathrm{TM}}$ Mag-Bind Soil DNA Kit (Omega Bio-tek, Inc., Norcross, GA, USA) according to the manufacturer's specifications. The integrity of DNA was detected by agarose gel electrophoresis (UVP, Upland, CA, USA) and the Qubit2.0 DNA detection kit (Life Tech, Shanghai, China). Polymerase chain reaction (PCR) amplification was performed on a PCR instrument $\left(\mathrm{T} 100^{\mathrm{TM}}\right.$ Thermal Cycler, BIO-RAD, Hercules, CA, USA). The 16S rRNA genes were amplified by three rounds of PCR for archaea. The primers were 340F (5'-CCCTAYGGGGYGCASCAG-3') and 1000R (5'-GGCCATGCACYWCYTCTC-3') in the first round, and were 349F (5'-CCCTACACGACGCTCTTCCGATCTN(barcode)GYGCASCAGKCGMGAAW- $3^{\prime}$ ) and 806R (5'-GACTGGAGTTCCTTGGCACCCGAGAATTCCAGGACTACVSGGGTATCTAAT-3') in the second round. The genes were then PCR-amplified with Illumina nested primers in the third round. For bacteria, there were two rounds of PCR amplification, using the primers 341F (5'-CCCTACACGACGCTCTTCCGATCTG(barcode)CCTACGGGNGGCWGCAG-3') and 805R (5'-GACTGGAGTTCCTTGGCACCCGAGAATTCCAGACTACHVGGGTATCTAATCC $3^{\prime}$ ) in the first round, and then Illumina nested primers in the second round.

\subsection{High-Throughput Pyrosequencing Analysis}

The PCR products were sequenced through Illumina Miseq ${ }^{\mathrm{TM}}$, and the raw data were then transformed to sequenced reads through CASAVA Base Calling and deposited under accession number SRP131631 in the NCBI SRA database. The raw sequences were wiped off the primer sequences using cutadapt and clustered into operational taxonomic units using Usearch. A total of 295,925 and 282,765 effective 16S rRNA sequences were retrieved with average lengths of $452.91 \mathrm{bp}$ and $417.18 \mathrm{bp}$ for bacteria and archaea, respectively. Richness and diversity estimators (Shannon, ACE, and Chao1 indices) were calculated using MOTHUR. The microbial community structures were classified by blastn in Blast (coverage $>90 \%$ ), and the comparison of metabolism was conducted using PICRUSt and STAMP.

\section{Conclusions}

The results of the present study suggest that that mesophilic AD of OFMSW showed better performance than thermophilic AD during both the adaptive phase and the OLR increasing phase. Larger shifts in the bacterial community were observed in the TR along with OLR elevation. 
With respect to methanogens, Methanothrix dominated in the MR while Methanosarcina was favored in the TR. Variations in the mode and efficiency of metabolism between the MR and TR resulted in different performances with efficiency mainly related to the limiting hydrolytic acid step.

Supplementary Materials: The following are available online at http:/ /www.mdpi.com/1996-1073/11/4/952/s1. Table S1: Basic characteristics of the food waste used in this study.

Acknowledgments: This work was funded by Guangdong Application Achievement Project (2017B020238005), Guangzhou science and technology project (201803030007) and Guangdong Technology Program of Industrial High Technology (2013B010204053).

Author Contributions: Xiaoying Kong, Tao Xing, Yi Zhang, and Yong Sun conceived and designed the experiments; Yiming Gao and Xingjian Luo performed the experiments; Yiming Gao analyzed the data; Yongming Sun contributed reagents/materials/analysis tools; Yiming Gao wrote the paper.

Conflicts of Interest: The authors declare no conflict of interest.

\section{References}

1. Murphy, J.D.; McKeogh, E. Technical, economic and environmental analysis of energy production from municipal solid waste. Renew. Energy 2004, 29, 1043-1057. [CrossRef]

2. Griffin, M.E.; McMahon, K.D.; Mackie, R.I.; Raskin, L. Methanogenic population dynamics during start-up of anaerobic digesters treating municipal solid waste and biosolids. Biotechnol. Bioeng. 1998, 57, 342-355. [CrossRef]

3. Song, Y.C.; Kwon, S.J.; Woo, J.H. Mesophilic and thermophilic temperature co-phase anaerobic digestion compared with single-stage mesophilic- and thermophilic digestion of sewage sludge. Water Res. 2004, 38, 1653-1662. [CrossRef] [PubMed]

4. Kang, X.; Sun, Y.; Li, L.; Kong, X.; Yuan, Z. Improving methane production from anaerobic digestion of Pennisetum Hybrid by alkaline pretreatment. Bioresour. Technol. 2018, 255, 205-212. [CrossRef] [PubMed]

5. Panepinto, D.; Genon, G. Analysis of the extrusion as a pretreatment for the anaerobic digestion process. Ind. Crop. Prod. 2016, 83, 206-212. [CrossRef]

6. Ahring, B.K. Perspectives for anaerobic digestion. In Biomethanation I; Ahring, B.K., Ed.; Springer: Berlin/Heidelberg, Germany, 2003; Volume 81, pp. 1-30.

7. Bayr, S.; Rantanen, M.; Kaparaju, P.; Rintala, J. Mesophilic and thermophilic anaerobic co-digestion of rendering plant and slaughterhouse wastes. Bioresour. Technol. 2012, 104, 28-36. [CrossRef] [PubMed]

8. Kim, M.; Ahn, Y.H.; Speece, R.E. Comparative process stability and efficiency of anaerobic digestion; mesophilic vs. thermophilic. Water Res. 2002, 36, 4369-4385. [CrossRef]

9. Ma, Q.; Shen, F.; Yuan, H.R.; Zou, D.X.; Liu, Y.P.; Zhu, B.N.; Li, X.J. Investigation on anaerobic digestion of the organic fraction of municipal solid waste (OFMSW) after pretreatment of fast aerobic fermentation. Fresenius Environ. Bull. 2015, 24, 1039-1046.

10. Muha, I.; Zielonka, S.; Lemmer, A.; Schonberg, M.; Linke, B.; Grillo, A.; Wittum, G. Do two-phase biogas plants separate anaerobic digestion phases?-A mathematical model for the distribution of anaerobic digestion phases among reactor stages. Bioresour. Technol. 2013, 132, 414-418. [CrossRef] [PubMed]

11. Gujer, W.; Zehnder, A.J.B. Conversion processes in anaerobic-digestion. Water Sci. Technol. 1983, 15, $127-167$.

12. Schievano, A.; D'Imporzano, G.; Malagutti, L.; Fragali, E.; Ruboni, G.; Adani, F. Evaluating inhibition conditions in high-solids anaerobic digestion of organic fraction of municipal solid waste. Bioresour. Technol. 2010, 101, 5728-5732. [CrossRef] [PubMed]

13. Nelson, M.C.; Morrison, M.; Yu, Z.T. A meta-analysis of the microbial diversity observed in anaerobic digesters. Bioresour. Technol. 2011, 102, 3730-3739. [CrossRef] [PubMed]

14. Ye, L.; Zhang, T. Bacterial communities in different sections of a municipal wastewater treatment plant revealed by $16 \mathrm{~S}$ rDNA 454 pyrosequencing. Appl. Microbiol. Biotechnol. 2013, 97, 2681-2690. [CrossRef] [PubMed]

15. Riviere, D.; Desvignes, V.; Pelletier, E.; Chaussonnerie, S.; Guermazi, S.; Weissenbach, J.; Li, T.; Camacho, P.; Sghir, A. Towards the definition of a core of microorganisms involved in anaerobic digestion of sludge. ISME J. 2009, 3, 700-714. [CrossRef] [PubMed] 
16. Guo, X.H.; Wang, C.; Sun, F.Q.; Zhu, W.J.; Wu, W.X. A comparison of microbial characteristics between the thermophilic and mesophilic anaerobic digesters exposed to elevated food waste loadings. Bioresour. Technol. 2014, 152, 420-428. [CrossRef] [PubMed]

17. Oleszkiewicz, J.A.; Marstaller, T.; McCartney, D.M. Effects of ph on sulfide toxicity to anaerobic processes. Environ. Technol. Lett. 1989, 10, 815-822. [CrossRef]

18. Ripley, L.E.; Boyle, W.C.; Converse, J.C. Improved alkalimetric monitoring for anaerobic-digestion of high-strength wastes. J. Water Pollut. Control Fed. 1986, 58, 406-411.

19. Poggivaraldo, H.M.; Tingley, J.; Oleszkiewicz, J.A. Inhibition of growth and acetate uptake by ammonia in batch anaerobic-digestion. J. Chem. Technol. Biotechnol. 1991, 52, 135-143. [CrossRef]

20. Hansen, K.H.; Angelidaki, I.; Ahring, B.K. Anaerobic digestion of swine manure: Inhibition by ammonia. Water Res. 1998, 32, 5-12. [CrossRef]

21. Yamada, T.; Sekiguchi, Y.; Hanada, S.; Imachi, H.; Ohashi, A.; Harada, H.; Kamagata, Y. Anaerolinea thermolimosa sp. nov., Levilinea saccharolytica gen. nov., sp. nov and Leptolinea tardivitalis gen. nov., so. nov., novel filamentous anaerobes, and description of the new classes anaerolineae classis nov and Caldilineae classis nov in the bacterial phylum Chloroflexi. Int. J. Syst. Evol. Microbiol. 2006, 56, 1331-1340. [PubMed]

22. Yamada, T.; Imachi, H.; Ohashi, A.; Harada, H.; Hanada, S.; Kamagata, Y.; Sekiguchi, Y. Bellilinea caldifistulae gen. nov., sp. nov and Longilinea arvoryzae gen. nov., sp. nov., strictly anaerobic, filamentous bacteria of the phylum Chloroflexi isolated from methanogenic propionate-degrading consortia. Int. J. Syst. Evol. Microbiol. 2007, 57, 2299-2306. [CrossRef] [PubMed]

23. Arun, A.B.; Chen, W.M.; Lai, W.A.; Chou, J.H.; Shen, F.T.; Rekha, P.D.; Young, C.C. Lutaonella thermophila gen. nov., sp. nov., a moderately thermophilic member of the family Flavobacteriaceae isolated from a coastal hot spring. Int. J. Syst. Evol. Microbiol. 2009, 59, 2069-2073. [CrossRef] [PubMed]

24. Wang, F.Q.; Shen, Q.Y.; Chen, G.J.; Du, Z.J. Mariniphaga sediminis sp. nov., isolated from coastal sediment. Int. J. Syst. Evol. Microbiol. 2015, 65, 2908-2912. [CrossRef] [PubMed]

25. Irgens, R.L. Meniscus, a new genus of aerotolerant, gas-vacuolated bacteria. Int. J. Syst. Bacteriol. 1977, 27, 38-43. [CrossRef]

26. Patel, B.; Morgan, H. A Combination of Stable Isotope Probing, Illumina Sequencing, and Co-occurrence Network to Investigate Thermophilic Acetate- and Lactate-Utilizing Bacteria. Microb. Ecol. 2018, 75, 113-122.

27. Zhang, Y.; Alam, M.A.; Kong, X.; Wang, Z.; Li, L.; Sun, Y.; Yuan, Z. Effect of salinity on the microbial community and performance on anaerobic digestion of marine macroalgae. J. Chem. Technol. Biotechnol. 2017, 92, 2392-2399. [CrossRef]

28. Demirel, B.; Scherer, P. The roles of acetotrophic and hydrogenotrophic methanogens during anaerobic conversion of biomass to methane: A review. Rev. Environ. Sci. Biotechnol. 2008, 7, 173-190. [CrossRef]

29. Kendall, M.M.; Boone, D.R. The Order Methanosarcinales. In The Prokaryotes: Volume 3: Archaea. Bacteria: Firmicutes, Actinomycetes; Dworkin, M., Falkow, S., Rosenberg, E., Schleifer, K.-H., Stackebrandt, E., Eds.; Springer: New York, NY, USA, 2006; pp. 244-256.

30. Garcia, J.L.; Patel, B.K.C.; Ollivier, B. Taxonomic phylogenetic and ecological diversity of methanogenic Archaea. Anaerobe 2000, 6, 205-226. [CrossRef] [PubMed]

31. Garcia, J.-L.; Ollivier, B.; Whitman, W.B. The Order Methanomicrobiales. In The Prokaryotes: Volume 3: Archaea. Bacteria: Firmicutes, Actinomycetes; Dworkin, M., Falkow, S., Rosenberg, E., Schleifer, K.-H., Stackebrandt, E., Eds.; Springer: New York, NY, USA, 2006; pp. 208-230.

32. Zhang, J.X.; Mao, L.W.; Zhang, L.; Loh, K.C.; Dai, Y.J.; Tong, Y.W. Metagenomic insight into the microbial networks and metabolic mechanism in anaerobic digesters for food waste by incorporating activated carbon. Sci. Rep. 2017, 7, 10. [CrossRef] [PubMed]

33. Cleceri, L.S.; Greenberg, A.E.; Eaton, A.D. Standard Methods for the Examination of Water and Waste Water; American Public Health Association: Washington, DC, USA, 1998; p. 113.

(C) 2018 by the authors. Licensee MDPI, Basel, Switzerland. This article is an open access article distributed under the terms and conditions of the Creative Commons Attribution (CC BY) license (http:/ / creativecommons.org/licenses/by/4.0/). 